\title{
Using high-resolution beach surveys to assess geomorphologic change within the Salinas Subcell (Monterey Bay, CA) before and after the 2015/2016 EI Niño
}

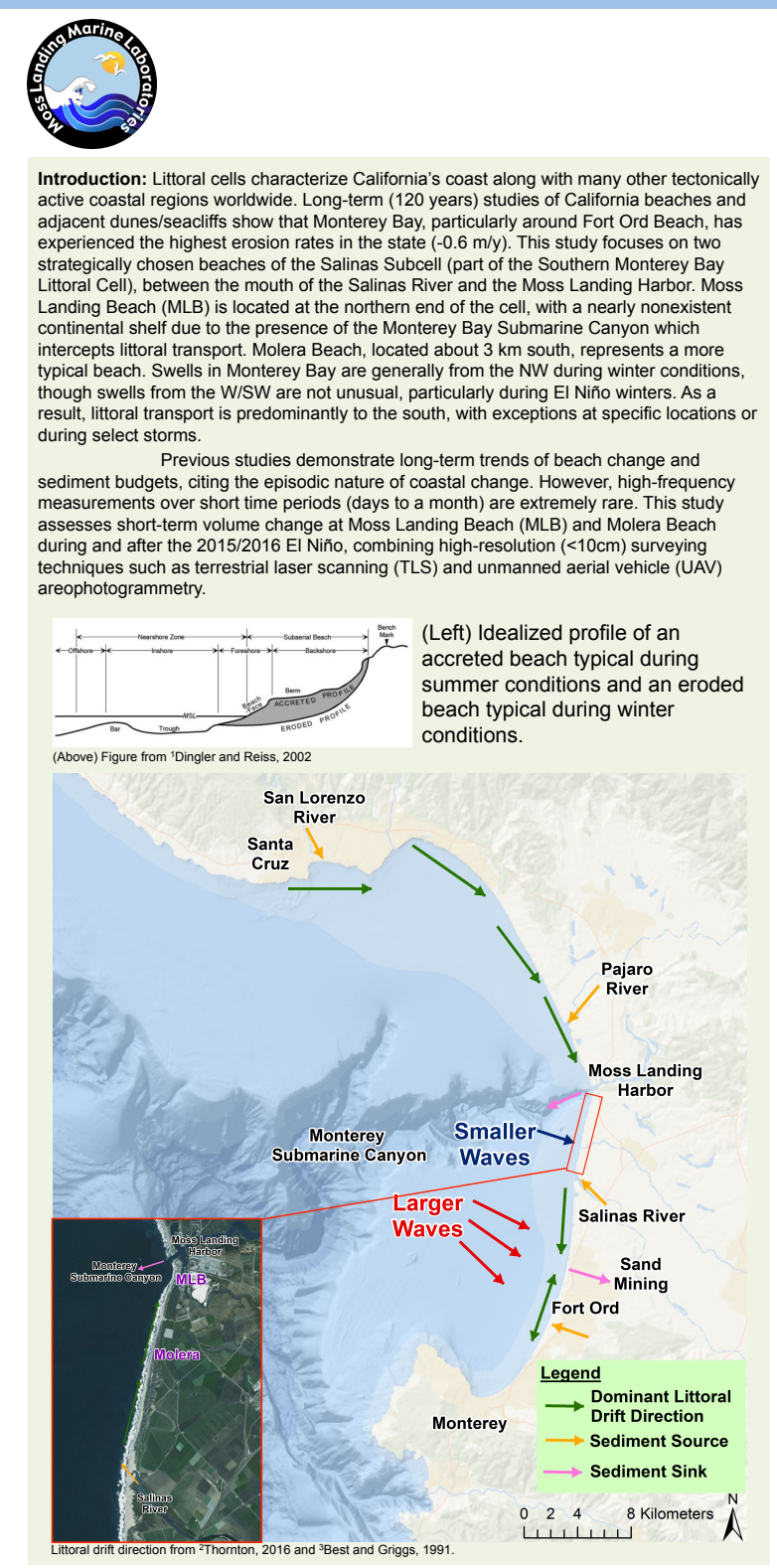

Tyler Barnes \& Ivano Aiello

Moss Landing Marine Labs (contact: tbarnes@mlml.calstate.edu)
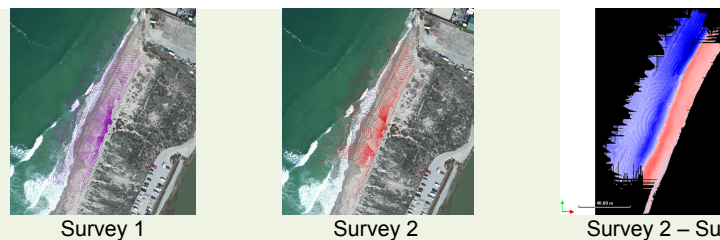

How to measure volume change when area covered varies from survey to survey?

1. Calculate the volume difference (survey 2 - survey 1 ) where surveys overlap.

2. Normalize by the planar area

Volume Change $\left(\mathrm{m}^{3} / \mathrm{m}^{2}\right)=($ Survey $2-$ Survey 1$) /$ Planar Area
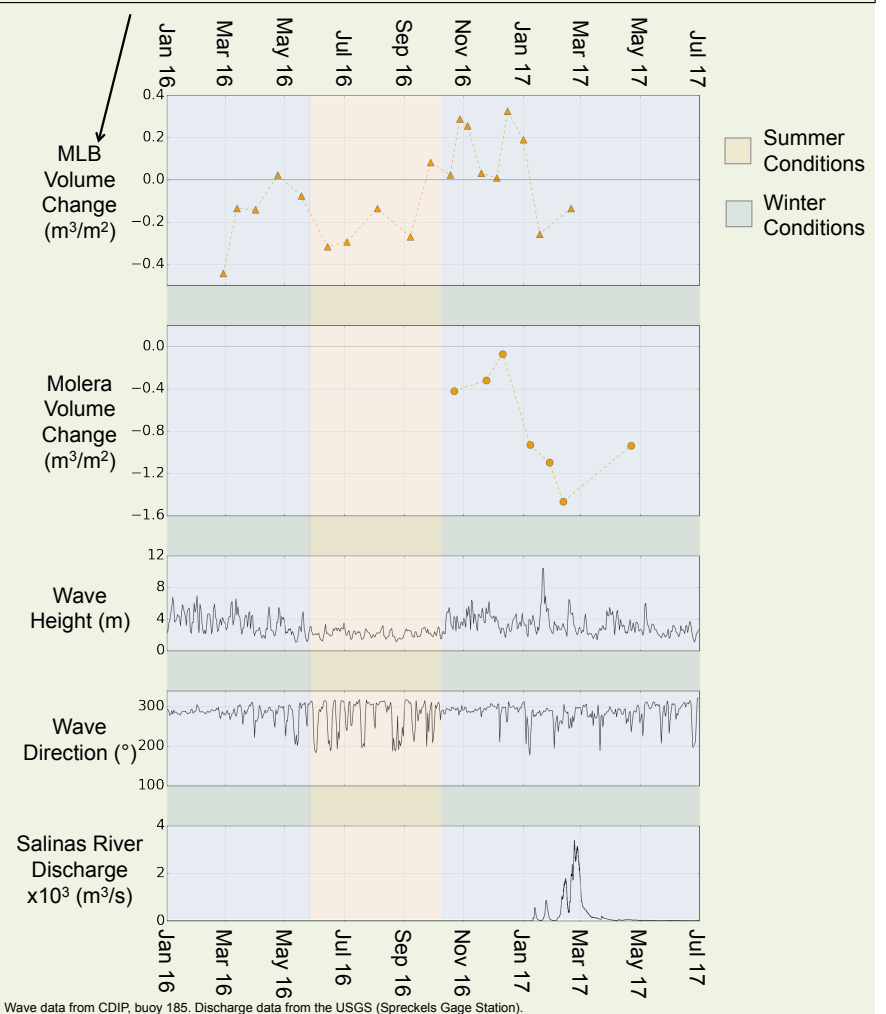

How does short-term beach variability compared to long-term trends and the sediment budget?

Extrapolate volume change to the area of the Salinas Subcell:

1. Assume normalized volume change is representative of the Salinas Subcell.

2. Estimate the length of the subcell and the average beach width.

3. Multiply normalized volume change by the length and width of the subcell.

Extrapolated Volume

$\times 5,500 \mathrm{~m} \times 35 \mathrm{~m}$ $\left(m^{3}\right)$ $\left(\mathrm{m}^{3} / \mathrm{m}^{2}\right)$

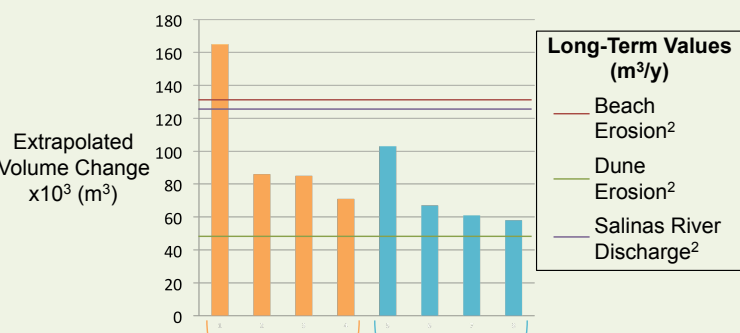

Short-term $\rightarrow$ Beach Loss Beach Gain

Main Findings:

Short-term beach variability (days to a month) within the Salinas Subcel is on the same order of magnitude as previous estimates of yearly components of the sediment budget for Southern Monterey Bay.

MLB experiences quick pulses of deposition following select erosional

MLB does not follow the expected accreted beach profile during summer conditions and eroded beach profile during winter conditions.

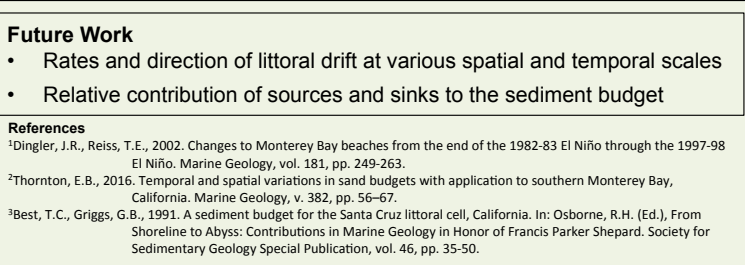

